\title{
PROSES DESAIN PENGEMBANGAN DIGESTER BIOGAS UMT 2017 UNTUK PEMANFAATAN ENERGI TERBARUKAN DENGAN BAHAN BAKU KOTORAN TERNAK SAPI
}

\author{
Fanni Fattah, Angger Ali Kahfi \\ Program Studi Teknik mesin, Fakultas teknik, Universitas Muhammadiyah Tangerang, \\ Jl. Perintis Kemerdekaan I, No.33, Cikokol, Tangerang, Banten 15118, Indonesia \\ Email : anggerali.k@gmail.com
}

\begin{abstract}
ABSTRAK
Potensi kotoran ternak sapi di Desa Kedung Dalem sebagai energi alternatif, yaitu sebagai bahan pembuatan biogas pengganti minyak tanah/gas LPG sebenarnya cukup besar namun belum banyak dimanfaatkan, bahkan dapat menimbulkan masalah pencemaran dan kesehatan lingkungan, karena umumnya kotoran sapi dibuang begitu saja atau dibuang ditempat pembuangan akhir. Untuk memanfaatkan kotoran sapi menjadi energi alternatif penggati minyak tanah/gas LPG, perlu suatu alat untuk penghasil gas metan yang terkandung dalam kotoran sapi untuk dijadikan biogas.

Pembuatan Digester biogas UMT 2017 pada kotoran sapi, sangat membantu pengembangan sistem daur ulang kotoran sapi untuk diproduksi menjadi biogas, sebagai pengganti minyak tanah (BBM)/gas LPG yang pada akhir-akhir ini sudah sulit untuk dicari. Penelitian ini bertujuan untuk mendesain alat digester biogas pada kotoran sapi menjadi biogas yang lebih fleksibel, lebih mudah cara pengoprasian dan biaya pembuatan yang lebih murah, serta bermanfaat bagi peternak sapi desa kedung dalem. Penelitian ini menghasilkan beberapa opsi desain alat digester biogas, sesuai dengan spesifikasi kebutuhan/target desain yang telah ditentukan. Dari opsi desain yang dibuat, maka dipilihlah desain yang paling baik yaitu desain 3, dari perbandingan antar desain dan target desain yang telah ditentukan.
\end{abstract}

Kata kunci : Performance, desain, digester, biogas

\section{PENDAHULUAN}

Beberapa tahun terakhir ini energi merupakan persoalan yang krusial didunia. Peningkatan permintaan energi yang disebabkan oleh pertumbuhan populasi penduduk dan menipisnya sumber cadangan minyak dunia serta permasalahan emisi dari bahan bakar fosil memberikan tekanan kepada setiap Negara untuk segera memproduksi dan menggunakan energi terbaharukan. Selain itu, peningkatan harga minyak dunia hingga mencapai 100 U\$ per barel juga menjadi alasan yang serius yang menimpa banyak negara didunia terutama Indonesia. Dalam situasi seperti ini pencarian, pengembangan, dan penyebaran teknologi energi non BBM yang ramah lingkungan menjadi penting, terutama ditujukan pada keluarga miskin sebagai golongan yang banyak terkena dampak kenaikan BBM. Salah satu teknologi energi yang sesuai dengan persyaratan tersebut adalah teknologi biogas (Darsin, 2006).

Dengan melihat berbagai macam energi yang digunakan dalam kehidupan sehari-hari, maka penulis akan memaparkan tentang pengolahan limbah peternakan sapi melalui proses anaerob atau fermentasi yang dapat menghasilkan biogas menjadi salah satu jenis bioenergi dengan memfokuskan pada Simplikasi Desain, Model dan Operasional Pembuatan Biogas dari Kotoran Sapi. Model digester saat ini umumnya menetap (Permanen), berukuran sangat besar dan dibuat didalam tanah. Penulis beringinan merubah digester menjadi model minimalis serta bisa dipindah tempatkan ke lokasi manapun (Portable) untuk mendapatkan efisiensi proses pembuatan, biaya dan lokasi (Space).

Dengan memperhatikan uraian latar belakang di atas, maka masalah dalam penelitian ini dapat diidentifikasi sebagai berikut :

1. Bagaimana memanfaatkan kotoran sapi di Desa Kedung Dalem agar dapat dijadikan energi biogas.

2. Desain digester biogas seperti apa yang dapat bermanfaat untuk peternak di Desa Kedung Dalem.

3. Bagaimanakah proses desain digester biogas yang dapat menghasilkan digester biogas yang sesuai untuk peternak di Desa Kedung Dalem.

\section{A. Biogas \\ II. LANDASAN TEORI \\ Biogas adalah gas yang berasal dari kotoran makhluk hidup, baik dari hewan maupun tanaman.}


Apabila kotoran hewan atau bahan tanaman telah membusuk, maka akan keluar gas. Gas ini yang disebut sebagai biogas. Biogas adalah gas yang mudah terbakar (flammable) yang dihasilkan dari proses fermentasi bahan-bahan organik oleh bakteri-bakteri anaerob. Biogas merupakan salah satu jenis energi yang dapat dibuat dari banyak jenis bahan buangan dan bahan sisa, semacam sampah, kotoran ternak, jerami, enceng gondok serta bahan organik lainnya (Pambudi, 2005).

Menurut Haryati (2006), pembentukan biogas meliputi tiga tahap proses yaitu :

1. Hidrolisis, pada tahap ini terjadi penguraian bahan-bahan organik mudah yang larut dan pemecahan bahan organik yang komplek menjadi bahan sederhana dengan bantuan air (perubahan struktur bentuk polimer menjadi bentuk monomer).

2. Pengasaman, pada ini tahap pengasaman komponen monomer (gula sederhana) yang terbrntuk pada tahap hidrolisis akan menjadi bahan makanan bagi bakteri pembentuk asam. Produk akhir dari perombakan gula-gula sederhana yaitu asam asetat, propionate, format, laktat, alkohol, dan sedikit butirat, gas karbondioksida, hydrogen dan ammonia.

3. Matanogenik, pada tahap matanogenik terjadi proses pembentukan gas metan. Bakteri pereduksi sulfat juga terdapat dalam proses ini yang akan mereduksi sulfat dan komponen sulfur lainnya menjadi hydrogen sulfide.

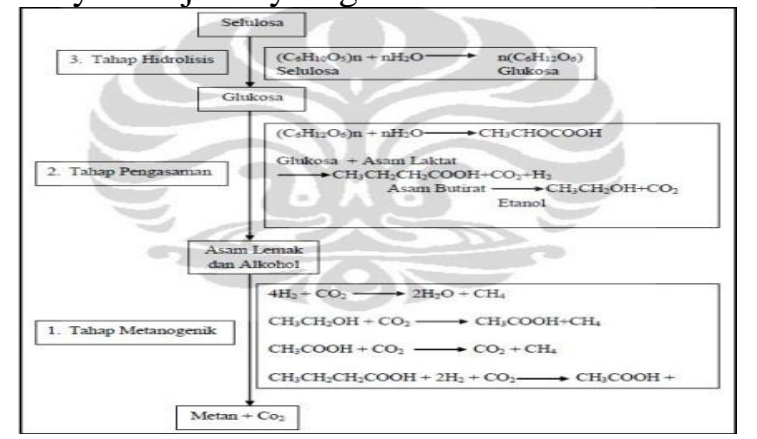

Gambar 1. Tahap Pembentukan Biogas

\section{B. Tipe Digester Biogas}

Pemilihan jenis biodigester disesuaikan dengan kebutuhan dan kemampuan pembiayaan / finansial. Biodigester sering disebut bangunan biogas yaitu sebuah tabung tertutup tempat limbah organik difermentasi, sehingga menghasilkan gas bio sebagai energi disertai dengan bahan penyubur dari limbah organik.

\section{Dari Segi Kontruksi}

a. Fixed dome (Kubah tetap)

Biodigester ini memiliki volume tetap sehingga produksi gas akan meningkatkan tekanan dalam reaktor (biodigester). Karena itu, dalam konstruksi ini gas yang terbentuk akan segera dialirkan ke pengumpul gas/gas bag di luar reaktor.

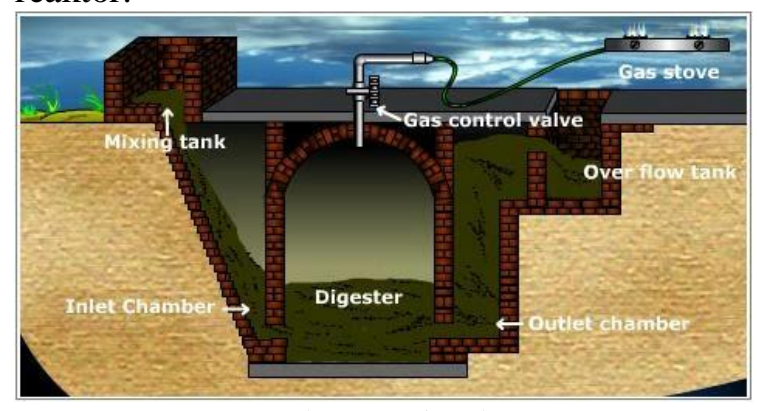

Gambar 2. Fixed Dome

b. Floating dome

Pada tipe ini terdapat bagian pada konstruksi reaktor yang bisa bergerak untuk menyesuaikan dengan kenaikan tekanan reaktor. Pergerakan bagian reaktor ini juga menjadi tanda telah dimulainya produksi gas dalam reaktor biogas. Pada reaktor jenis ini, pengumpul gas berada dalam satu kesatuan dengan reaktor tersebut.

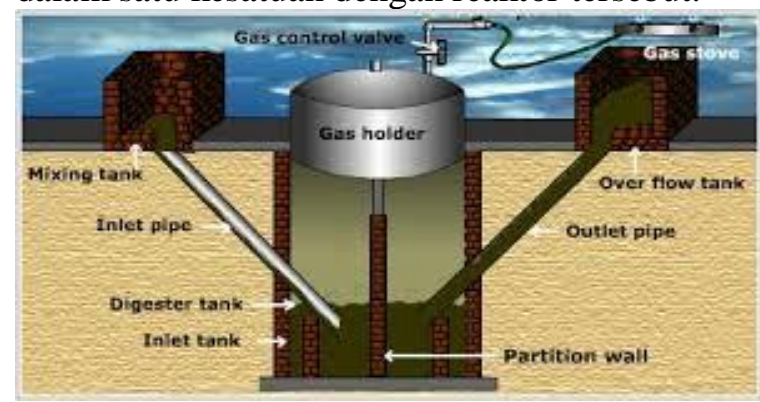

Gambar 3. Floating Dome

2. Dari segi aliran bahan baku reaktor biogas

a. Bak (batch)

Menurut Iman, 2008 (2008) Batch Process merupakan fermentasi dengan cara memasukan media dan inokulum secara bersamaan ke dalam bioreaktor dan pengambilan produk dilakukan pada akhir fermentasi.

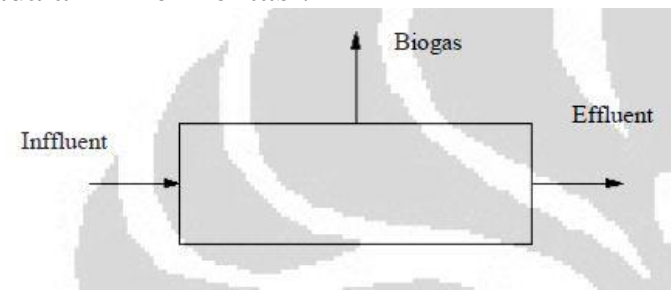

Gambar 4. Reaktor Tipe Bak (batch)

b. Mengalir (continues)

Pada cara Mengalir (Continues Process), pengaliran subtrat dan pengambilan produk dilakukan secara terus menerus (sinambung) setiap saat setelah diperoleh konsentrasi produk maksimal atau subtract pembatasnya mencapai konsentrasi yang hampir tetap (Rusmana, 2008). Dalam hal ini subtrat dan inokulum dapat ditambahkan bersama-sama secara terus menerus sehingga fase eksponensial dapat diperpanjang. 


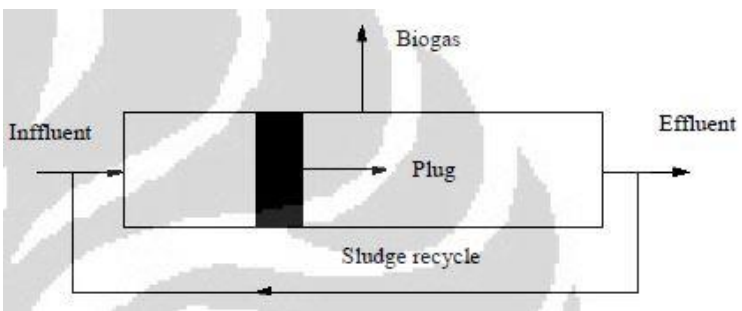

Gambar 5. Reaktor Tipe Mengalir (continuous)

\section{Alur Proses Pembentukan Biogas}

Alur proses pembuatan biogas dari mulai kotoran sapi hingga menjadi gas dan menghasilkan api (Gambar 8) :

1. Mencampur kotoran ternak sapi dengan air sampai terbentuk lumpur/kental dengan perbandingan 1:1 pada bak penampung sementara. Bentuk lumpur akan mempermudah pemasukan kedalam digester.

2. Mengalirkan campuran kotoran sapi dan air kedalam digester melalui lubang pemasukan. Pada pengisian pertama kran gas yang ada diatas digester dibuka agar pemasukan lebih mudah dan udara yang ada didalam digester terdesak keluar.

3. Membuang gas yang pertama dihasilkan pada hari ke-1 sampai ke-8 karena yang terbentuk adalah gas $\mathrm{CO}_{2}$. Sedangkan pada hari ke-10 sampai hari ke-14 baru terbentuk gas metan $\left(\mathrm{CH}_{4}\right)$ dan $\mathrm{CO}_{2}$ mulai menurun. Pada komposisi $\mathrm{CH}_{4} 54 \%$ dan $\mathrm{CO}_{2} 27 \%$ maka biogas akan menyala.

4. Pada hari ke-14 gas yang terbentuk dapat digunakan untuk menyalakan api pada kompor gas atau kebutuhan lainnya. Mulai hari ke-14 ini kita sudah bisa menghasilkan energi biogas yang selalu terbarukan. Biogas ini tidak berbau seperti bau kotoran sapi. Selanjutnya, menunggu hingga penampung gas (gas bag) mengalami pengembangan atau terisi penuh.

5. Uji coba pengetesan nyala api dari gas yang sudah di tampung di gas bag.

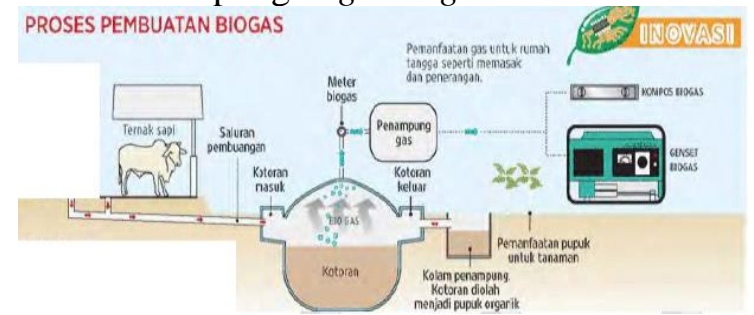

Gambar 6. Alur Proses Pembuatan Biogas

\section{Proses Desain Digester Biogas UMT 2017}

Proses desian digester biogas UMT 2017 adalah suatu proses gambar dan perhitungan dalam menentukan ukuran, posisi, tipe material, jumlah material dan biaya yang digunakan pada proses pembuatan biogas digester UMT 2017.
Dalam proses desain digester biogas UMT 2017, perlu diperhatikan beberapa aspek sebagai berikut :

1. Pemilihan Bahan dan Proses

Pemilihan bahan yang ada di sekitar manusia jarang sekali dipikirkan. Orang yang merancang rumah, mobil, aircraft, clothing, furniture dan produk lain atau sistem memberikan banyak perhatian untuk memilih bahan yang dipergunakannya.

2. Kriteria Pemilihan Bahan

Spesifikasi yang ada memiliki banyak pengaruh pada pemilihan bahan. Spesifikasi ini atau standar digunakan pada rencana ulang untuk memperbaiki produk.

3. Tegangan (Stress)

Semua bahan berubah bentuk karena pengaruh gaya. Ada yang kembali ke bentuk aslinya bila gaya dihilangkan, ada pula yang tetap berubah bentuk sedikit atau banyak, (Sears, 1944 terjemahan Soedarjana, 1986:236).

4. Faktor Keamanan (Factor of Safety)

Faktor keamanan adalah perbandingan antara beban kekuatan minimum material dibagi dengan pembebanan tegangan tertinggi yang terjadi pada material, $\mathrm{SF}=\mathrm{n}=$ Material strength / design load.

5. Fatigue

Fatigue atau kelelahan menurut (Zulhanif, 2002) didefinisikan sebagai proses perubahan struktur permanen progressive localized pada kondisi yang menghasilkan fluktuasi regangan dan tegangan dibawah kekuatan tariknya dan pada satu titik atau banyak titik yang dapat memuncak menjadi retak (crack) atau patahan (fracture) secara keseluruhan sesudah fluktuasi tertentu.

6. Advenced Product Quality Planning

APQP/perencanaan kualitas produk lanjutan adalah pendekatan terstruktur untuk desain produk dan proses. Kerangka kerja ini adalah seperangkat persyaratan kualitas standar yang memungkinkan pemasok merancang produk yang memuaskan pelanggan.

7. Korosi

Korosi di definisikan sebagai penurunan mutu logam akibat reaksi elektrokimia dengan lingkungannya (Trethewey, 1991). Pada peristiwa korosi, logam akan mengalami oksidasi, sedangkan oksigen (udara) mengalami reduksi.

\section{METODE PENELITIAN}

\section{Metode Penelitian}

Metode penelitian yang digunakan adalah metode rekayasa (suatu kegiatan rancang) yang tidak rutin, 
sehingga di dalamnya terdapat kontribusi baru, baik dalam bentuk proses maupun produk/prototype.

\section{Lokasi Penelitian}

Penelitian ini dilakukan pada salah satu Rumah Penduduk (Bapak Khoirul Munabidin) di Desa Kedung Dalem Kecamatan Mauk Kabupaten Tangerang Banten.

\section{Alat dan Bahan}

Agar penelitian dapat dilakukan dengan baik, maka dalam hal ini dibutuhkan beberapa alat dan bahan yang dapat mendukung jalannya penelitian. Adapun alat dan bahan yang digunakan adalah sebagai berikut :

1) Alat

- Mesin las listrik

- Mesin bor tangan

- Masin gerinda tangan

- Gergaji besi

- Meteran

- Kunci Inggris

- Kunci Pipa

- Penggaris dan Spidol

2) Bahan

- Drum 220 liter (1 unit)

- Plat Besi 50 x 50 x $5 \mathrm{~mm}-6000 \mathrm{~mm}$ untuk pembuatan rangka.

- Plastik gas bag ukuran diameter $50 \mathrm{~cm}$ tinggi $80 \mathrm{~cm}$ untuk penampung gas.

- Selang karet atau selang plastik untuk mengalirkan gas.

- Kompor gas dan Manometer masingmasing sebanyak 1 buah.

- Paralon PVC, Lem PVC. Lem Sealant dan Valve PVC.

\section{Performance/Kebutuhan Desain}

Penelitian ini bertujuan memperoleh desain alat digester dari kotoran ternak sapi menjadi energi alternatif yang bisa dimanfaatkan sebagai biogas sebagai pengganti minyak tanah, gas LPG serta daya listrik. Desain alat ini diharapkan, sebagai solusi untuk mengatasi kekurangan energi, terutama mengurangi subsidi BBM. Melalui metode observasi didapat beberapa ketentuan desain dalam pembuatan digester biogas UMT 2017 yang tertera pada tabel berikut :

Tabel 1. Spesisifikasi Kebutuhan Desain

\begin{tabular}{|l|c|}
\hline \multicolumn{1}{|c|}{ Performasi } & Target Desain \\
\hline Biaya Bahan Baku & $\leq$ Rp. $2.500 .000,-$ \\
\hline Biaya Manufaktur & $\leq$ Rp. $1.000 .000,-$ \\
\hline $\begin{array}{l}\text { Ketahanan Beban } \\
\text { Statis }\end{array}$ & MIN SOF $\geq 3.0$ \\
\hline $\begin{array}{l}\text { Ketahanan Beban } \\
\text { Dinamis }\end{array}$ & MIN SOF $\geq 3.0$ \\
\hline
\end{tabular}

\begin{tabular}{|l|c|}
\hline Analisa Fatigue & MIN Load Factor/SOF $\geq$ \\
\hline $\begin{array}{l}\text { Berat }(\text { Weight }) \text { Alat } \\
\text { Keseluruhan }\end{array}$ & $\leq 60 \mathrm{~kg}$ \\
\hline Kapasitas Gas & $\geq 0.5 \mathrm{~m}^{3}$ \\
\hline Energi & $\geq 7200000$ Joule \\
\hline
\end{tabular}

\section{Alur Proses Penelitian}

Alur proses penelitian digester biogas UMT 2017 dapat dilihat pada gambar dibawah ini :

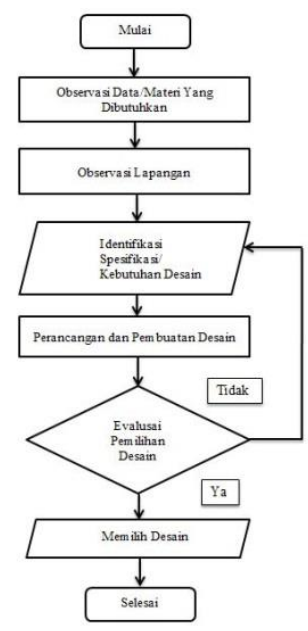

Gambar 7. Alur Proses Penelitian

\section{ANALISA DAN PEMBAHASAN}

\section{Evolusi Desain}

Pada pembuatan digester biogas UMT 2017 ini melalui beberapa tahap desain untuk menentukan desain mana yang akan dipilih dengan membandingkan antara desain satu dengan yang lain serta perbandingan dari target desain yang telah ditentukan.

Adapun tahap desain yang dibuat ialah desain 1, desain 2 dan desain 3, dimana masing-masing desain memiliki kelebihan dan kekurangannya.

a) Desain 1

Desain ini adalah desain awal, dimana masih mencari-cari referensi pembuatan digester portable dari berbagai sumber dan menjadi gambaran dari digester biogas yang akan dibuat.

Desain 1 mempunyai kelebihan dan kelemahan, yaitu :

- Kelebihan
a. Proses manufaktur lebih mudah
b. Biaya pembuatan lebih murah

- Kelemahan

a. Kapasitas gas yang dihasilkan lebih kecil

b. Pengoprasian yang masih sulit karena masih tahap gambaran desain. 


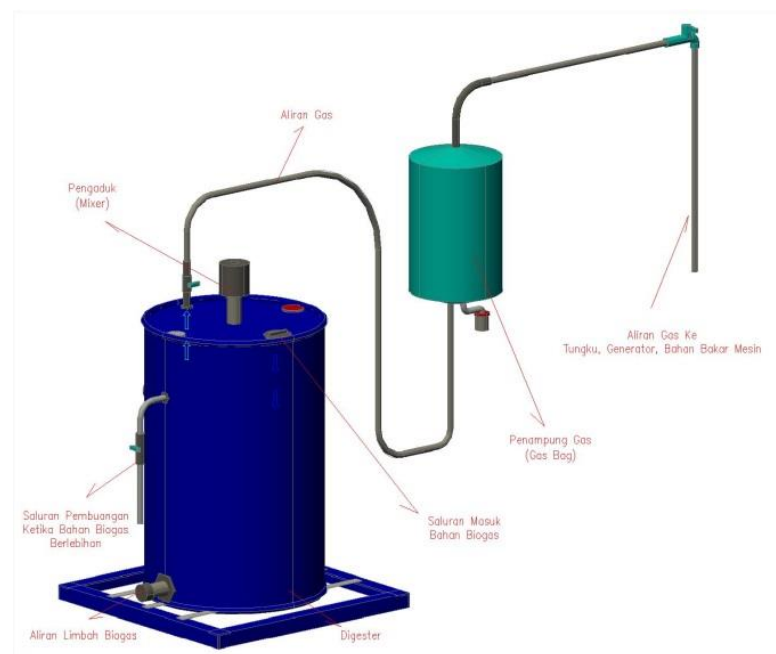

Gambar 8. Desain 1

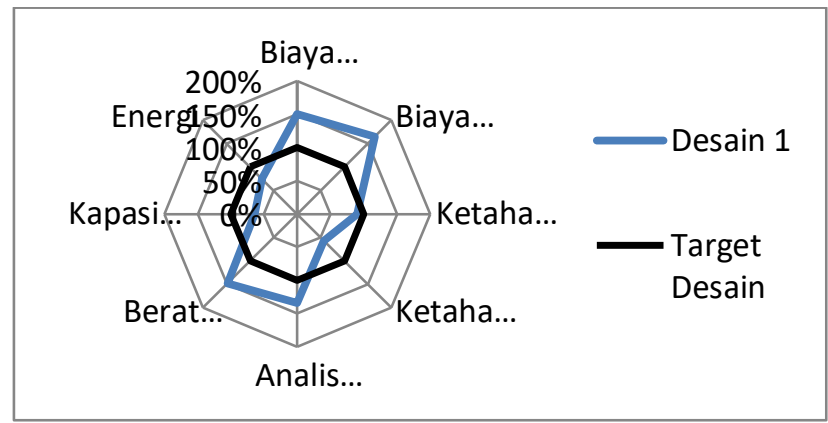

Gambar 9. Grafik Performance Desain 1

\section{b) Desain 2}

Desain ini adalah desain uji coba pertama pembuatan digester karena dari ukuran komponenkomponennya beberapa sudah ditentukan. Pada desain ini mesin pengaduk menggunakan mesin modifikasi yang manufaktur dan biayanya lebih tinggi.

Desain 2 mempunyai kelebihan dan kelemahan, yaitu :

- Kelebihan

a. Kapasitas gas yang dihasilkan sesuai target desain

b. Fleksibilitas dan cara pengoprasian yang lebih mudah

- Kelemahan

a. Proses manufaktur yang lebih sulit

b. Biaya lebih mahal

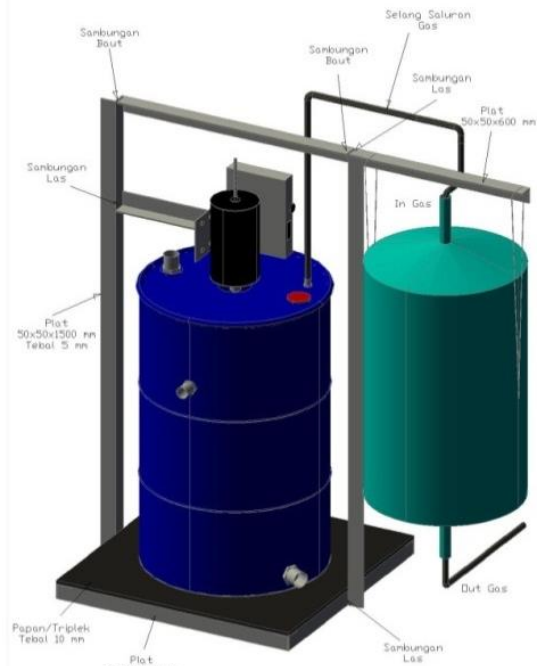

Gambar 10. Desain 2

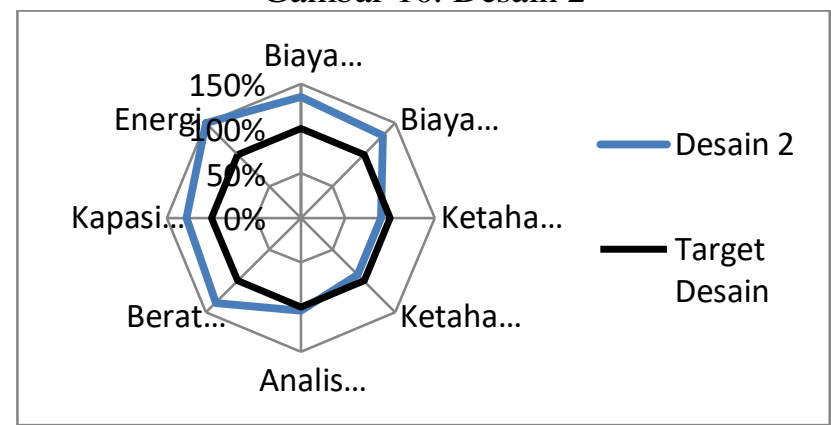

Gambar 11. Grafik Performance Desain 2

c) Desain 3

Desain ini adalah desain final dari pembuatan digester biogas UMT 2017, dimana semua komponen telah tergambar dan telah ditentukan spesifikasi dan penempatannya sebelum proses manufaktur dan asembling.

Desain 3 mempunyai kelebihan dan kelemahan, yaitu :

- Kelebihan

a. Kapasitas gas yang dihasilkan sesuai target desain

b. Fleksibilitas dan cara pengoprasian yang lebih mudah

c. Ketahanan beban yang tinggi

- Kelemahan

a. Proses manufaktur yang lebih sulit

b. Biaya lebih mahal 


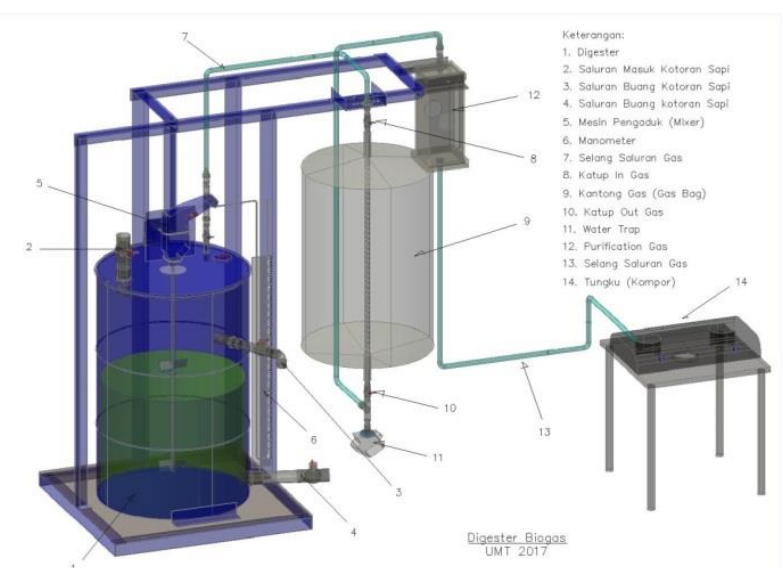

Gambar 12. Desain 3

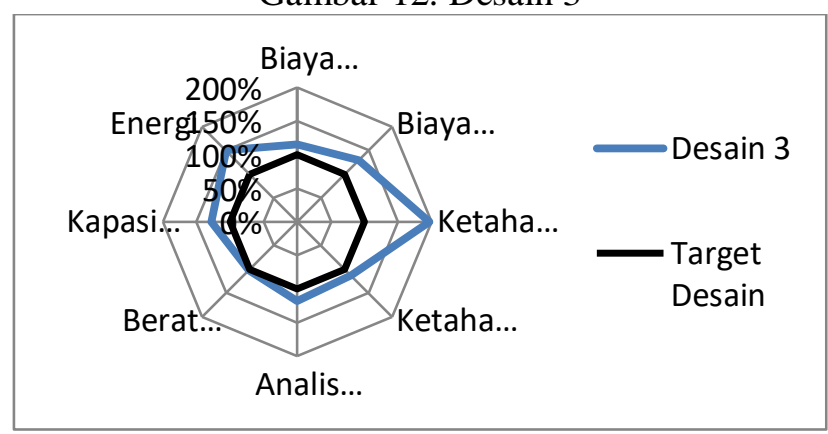

Gambar 13. Grafik Performance Desain 3

\section{Evalusai Desain Digester Biogas UMT 2017}

Pemanfaatan energi dari instalasi digester biogas UMT 2017 ini hanya melalui energi panas dari pembakaran gas methana yang terkandung di dalamnya, dengan beberapa ujicoba pemanfaatan dan rangkaian pemanfaatan energinya.

Dari beberapa desain yang telah dibuat, maka perlu dilakukan penyelidikan untuk setiap desain dalam pembuatan digester biogas UMT 2017. Tahap pemilihan desain dijelaskan sebagai berikut :

a) Menyusun Kriteria Desain

Kriteria desain disusun berdasarkan hasil penelitian dan mengakaji dari beberapa sumber serta dari ujicoba alat. Tahap kriteria desain yang digunakan sebagai pertimbangan adalah sebagai berikut :
a. Biaya pembuatan digester
b. Biaya \& kemudahan manufaktur digester
c. Ketahanan beban statis, dinamis fatigue
d. Hasil gas yang didapatkan
e. Berat alat dari desain yang dibuat
f. Energi yang dihasilkan dari hasil gas

Dari kriteria yang digunakan untuk menentukan desain yang akan dipakai pada pembuatan digester biogas UMT 2017, maka dibuatlah perbandingan dari kriteria desain-desain tersebut yaitu sebagai berikut:

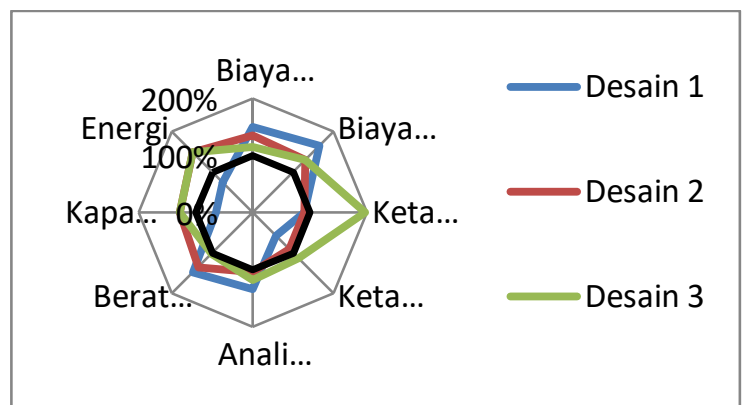

Gambar 14. Grafik Perbandingan Antar Desain dan Target Desain

Dari Gambar 14. dapat dijelaskan pada tabel berikut :

Tabel 2. Persentase Perbandingan Nilai Antar Desain dan Target Desain

\begin{tabular}{|l|c|c|c|c|}
\hline $\begin{array}{l}\text { Performa } \\
\text { si }\end{array}$ & $\begin{array}{c}\text { Desai } \\
\mathbf{n ~ 1}\end{array}$ & $\begin{array}{c}\text { Desai } \\
\mathbf{n} 2\end{array}$ & $\begin{array}{c}\text { Desai } \\
\mathbf{n ~ 3}\end{array}$ & $\begin{array}{c}\text { Targe } \\
\mathbf{t} \\
\text { Desai } \\
\mathbf{n}\end{array}$ \\
\hline $\begin{array}{l}\text { Biaya } \\
\text { Bahan } \\
\text { Baku }\end{array}$ & $150 \%$ & $135 \%$ & $115 \%$ & $100 \%$ \\
\hline $\begin{array}{l}\text { Biaya } \\
\text { Manufakt } \\
\text { ur }\end{array}$ & $165 \%$ & $130 \%$ & $130 \%$ & $100 \%$ \\
\hline $\begin{array}{l}\text { Ketahanan } \\
\text { Beban } \\
\text { Statis }\end{array}$ & $90 \%$ & $90 \%$ & $197 \%$ & $100 \%$ \\
\hline $\begin{array}{l}\text { Ketahanan } \\
\text { Beban } \\
\text { Dinamis }\end{array}$ & $57 \%$ & $90 \%$ & $113 \%$ & $100 \%$ \\
\hline $\begin{array}{l}\text { Analisa } \\
\text { Fatigue }\end{array}$ & $134 \%$ & $105 \%$ & $118 \%$ & $100 \%$ \\
\hline Berat Alat & $148 \%$ & $135 \%$ & $102 \%$ & $100 \%$ \\
\hline $\begin{array}{l}\text { Kapasitas } \\
\text { Gas }\end{array}$ & $64 \%$ & $128 \%$ & $128 \%$ & $100 \%$ \\
\hline Energi & $75 \%$ & $150 \%$ & $150 \%$ & $100 \%$ \\
\hline Rata-rata & $\mathbf{1 1 0 \%}$ & $\mathbf{1 2 0 \%}$ & $\mathbf{1 3 2 \%}$ & $\mathbf{1 0 0 \%}$ \\
\hline
\end{tabular}

b) Merangking Desain

Dari desain keseluruhan diketahui maka selanjutnya merangking desain berdasarkan nilai terbesar ke nilai terkecil. Rangking desain dapat dilihat pada tabel 3 .

Tabel 3. Rangking Desain

\begin{tabular}{|c|c|}
\hline Desain & Nilai Rata-rata \\
\hline Desain 3 & $132 \%$ \\
\hline Desain 2 & $120 \%$ \\
\hline Desain 1 & $110 \%$ \\
\hline
\end{tabular}

c) Memilih Desain

Dari data dan nilai rangking desain yang telah diketahui, maka desain yang digunakan pada pembuatan digester biogas UMT 2017 ini 
adalah desain 3, dengan alasan dan pertimbangan sebagai berikut :

1. Desain 3 memiliki nilai rata-rata tertinggi dari penentuan kriteria perbandingan antar desain dan target desain.

2. Desain 3 memiliki fleksibilitas dan cara pengoprasian yang lebih baik, karena semua komponen telah terpasang pada posisi yang tegambar pada desain.

3. Keamanan pada desain 3 sangat tinggi meski digunakan pengoprasian jangka panjang.

4. Gas yang dihasilkan melebihi ekspektasi dari target yang ditentukan dalam ujicoba pembuatan digester portable tipe batch.

5. Meski biaya yang digunakan paling tinggi tetapi biaya yang digunakan belum melewati biaya target desain yang telah ditentukan.

\section{Kesimpulan}

\section{PENUTUP}

Adapun kesimpulan dari laporan skripsi ini adalah sebagai berikut :

1) Melalui proses desain, maka didapatkan 3 tipe digester biogas dengan spesifikasi sebagai berikut :

a. Desain 1 Memiliki biaya pembuatan yang rendah dan proses manufaktur yang lebih mudah, tetapi kapasitas gas yang dihasilkan kurang dari target desain serta cara pengoprsian yang masih sulit.

b. Desain 2 memiliki fleksibilitas dan cara pengoprasian yang lebih mudah dan hasil gas yang didapat melebihi target desain, tetapi biaya pembuatan yang tinggi dan proses manufaktur yang sulit.

c. Desain 3 memiliki fleksibilitas dan cara pengoprasian yang lebih mudah, hasil gas yang didapat melebihi target desain serta mempunyai keamanan material yang tinggi, tetapi biaya pembuatan yang lebih tinggi dan proses manufaktur yang lebih sulit.

2) Setelah melakukan evaluasi desain, desain yang dipilih dalam pembuatan digester biogas UMT 2017 adalah desain 3, dari hasil perbandingan beberapa kriteria antar desain dan target desain, dengan alasan pertimbangan pemilihan sebagai berikut :

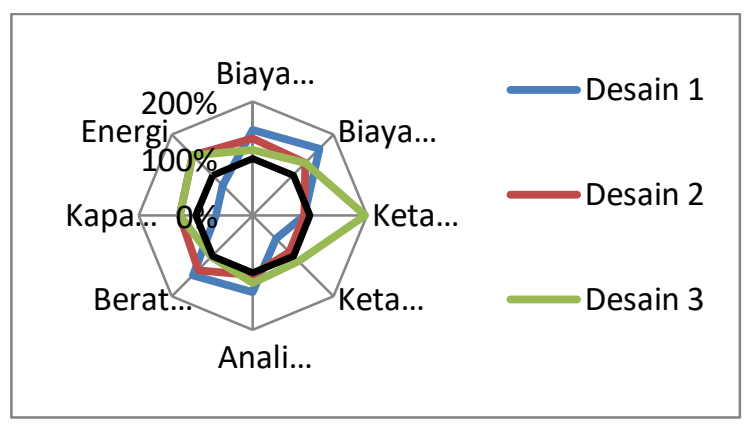

DAFTAR PUSTAKA

Sunil Kumar. First Published March, 2012. Biogas, in Croatia. Janeza Trdine, 510000 Rijeka, Croatia.

Darsin, M. 2006. Design of Biogas Circulator, Seminar Nasional Kreativitas Mesin Brawijaya 2006, Universitas Barawijaya, Malang.

Pambudi, N. Agung, 2005, Pemanfaatan Biogas Sebagai Energi Alternatif, , IPB.

Haryati, T. 2006. Biogas: Limbah Peternakan yang Menjadi Sumber Energi Alternatif. Jurnal Wartazoa.16: 160-169.

Rusmana, Iman., 2008. Sistem Operasi Fermentasi, Departemen Biologi FMIPA IPB, Bogor Jawa Barat.

Sears F. W. 1944., terjemahan P. J. Soedarjana, 1986., Mekanika, Panas dan Bunyi. Binacipta, Bandung.

Apa - Yang - Dimaksud - Dengan - Faktor -

Keamanan - Selasa, 06 Juni 2016 id.answers.yahoo.com/question/index?qid=2

0111001075004AA745KD

Zulhanif. 2002., Teses: Pengaruh Implantasi Ion Cromium Terhadap Ketahanan Fatique Baja Karbon Rendah. Yogyakarta. Universitas Gajah Mada.

Trethewey KR.. 1991, Korosi (Untuk Mahasiswa dan Rekayasawan), PT Gramedia Pustaka Utama, Jakarta.

APQP, Perencanaan Mutu Produk Lanjutan - Selasa, 01 Agustus 2017 http://quality-one.com/apqp/ 